\title{
Reduction of die roll height in duplex gears through a sheet-bulk metal forming method
}

\author{
Xiao-Long Sun ${ }^{1} \cdot$ Xin-Cun Zhuang ${ }^{1} \cdot$ Feng-Chun Yang $^{1} \cdot$ Zhen Zhao $^{1,2}$
}

Received: 31 July 2018/Accepted: 17 December 2018/Published online: 24 January 2019

(C) The Author(s) 2019

\begin{abstract}
In the existing shearing processes for fabricating parts such as duplex gears, die roll is difficult to avoid. Accordingly, a method based on sheet-bulk metal forming for fabricating a duplex gear with extremely small die roll in one stroke is proposed in the current work. The process could be divided into three stages according to the forming features: upsetting and shearing stage, lateral extrusion stage, and local filling stage. The die roll appeared in the shearing stage, which could be reduced in the subsequent extrusion and local filling stages. To reveal the underground mechanism, material flows under two situations, as a key factor to influence the forming quality, were compared and investigated. The results revealed that by controlling material flow, one could avoid the defects and reduce the die roll.
\end{abstract}

Keywords Die roll · Duplex gear part · Sheet-bulk metal forming $\cdot$ Lateral extrusion - Material flow

\section{Introduction}

The duplex gear, a key component in the transmission system, should be dimensionally accurate in order to function properly. Generally, duplex gears are fabricated

Zhen Zhao

zzhao@sjtu.edu.cn

1 Institute of Forming Technology and Equipment, School of Materials Science and Engineering, Shanghai Jiao Tong University, Shanghai 200030, People's Republic of China

2 National Engineering Research Center of Die \& Mold CAD, Shanghai Jiao Tong University, Shanghai 200030, People's Republic of China through machining or powder metallurgy (PM) methods [1]. However, manufacturing efficiency and material utilization rates are low in machining. In the PM method, heat and excess energy are required. Studies have also applied forming methods such as fine blanking [2] that require the use of a specific press with three dynamic motions. A significant problem associated with the fine blanking process is the appearance of die roll (shear droop/roll over) in the teeth located in areas I, II, and III as shown in Fig. 1.

The existence of the die roll would shorten the working length of a gear; therefore, various methods have been developed for reducing the die roll. Kondo and Maeda [3] proposed a different die shearing process in which dualdirectional extrusion could be used to achieve a small die roll. Kwak et al. [4] analyzed the effects of clearance on the die roll by conducting both theoretical predictions and experimental assessments. Ultrasonic vibration on a punch [5] and modified die structure [6] were applied during fine blanking to reduce the die roll. In addition, negative clearance could get smaller die roll in fine blanking [7]. Tanaka et al. [8] reported that a higher blank holding force and counterforce, a higher V-ring, and smaller clearance could be applied to reduce the die roll. Huang et al. [9] simulated fine blanking using different punch-die clearance levels; the die roll quality was improved by controlling the material flow in the local area. Luo et al. [10] developed a two-step compound fine blanking method that could significantly reduce the die roll of gear teeth. However, all the aforementioned methods proposed for die roll control put emphasis on a single-stage part, as shown in Fig. 1. Few studies have attempted to develop methods for controlling the die roll of area I in the duplex gear.

Recently, a new sheet metal forming concept, applying compressive stress to a sheet to obtain a sheet-shaped part with high-quality functional elements, was proposed [11]. 


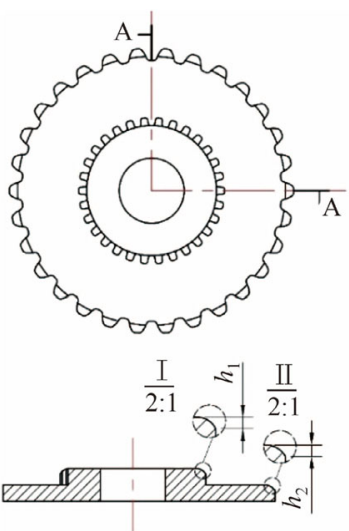

A-A
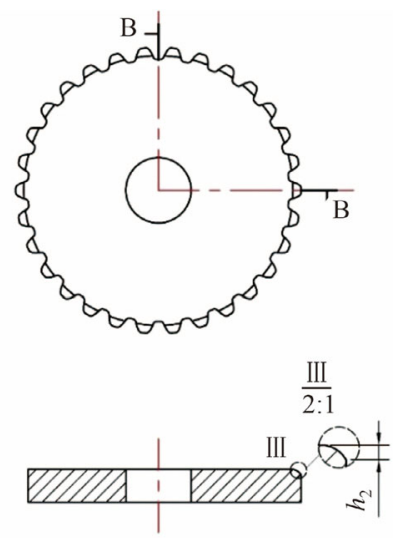

B-B

Fig. 1 Die roll in gear part fabricated through fine blanking

In Germany, this concept was called sheet-bulk metal forming (SBMF) [12], and in Japan as plate forging [13]. To obtain parts with various thicknesses, high accuracy, and complex shapes, material flow is regarded as the main influencing factor. In this study, an SBMF based method was developed to form duplex gear parts with extremely small die rolls in areas I and II, as presented in Fig. 1. To reveal the underground mechanism of small die rolls, experimental setup and numerical model are presented. By analyzing the influence of material flow on the formation of crack in the shearing zone and the die roll evolution of the inner teeth, the principle of die roll reduction is clarified.

\section{Experiment and numerical modeling}

\subsection{Experimental setup}

A duplex gear was chosen as the target part in this study. Figure 2 shows the gear, where $\mathrm{T}_{1}$ and $t_{1}$ represent the teeth in the outer area and their thickness, respectively; whereas $\mathrm{T}_{2}$ and $t_{2}$ represent the teeth in the shoulder area and their thickness, respectively. The teeth in the shoulder area can be divided into several types as shown in areas AG. Various tooth types were designed in one part to examine the die roll evolution in different forming stages and validate the generalizability of the proposed method. Table 1 lists the geometric characteristics of the tooth such as gear modulus, tooth length, corner angle, and corner radius.

The forming process is designed to complete in one stroke, and the whole process could be divided into three stages according to the forming features: upsetting and shearing stage, lateral extrusion stage and local filling stage. The principle of the duplex gear forming method is presented in Fig. 3. Firstly, a ring-shaped billet, cut from a sheet with the thickness of $t_{0}$, is placed on the stationary die

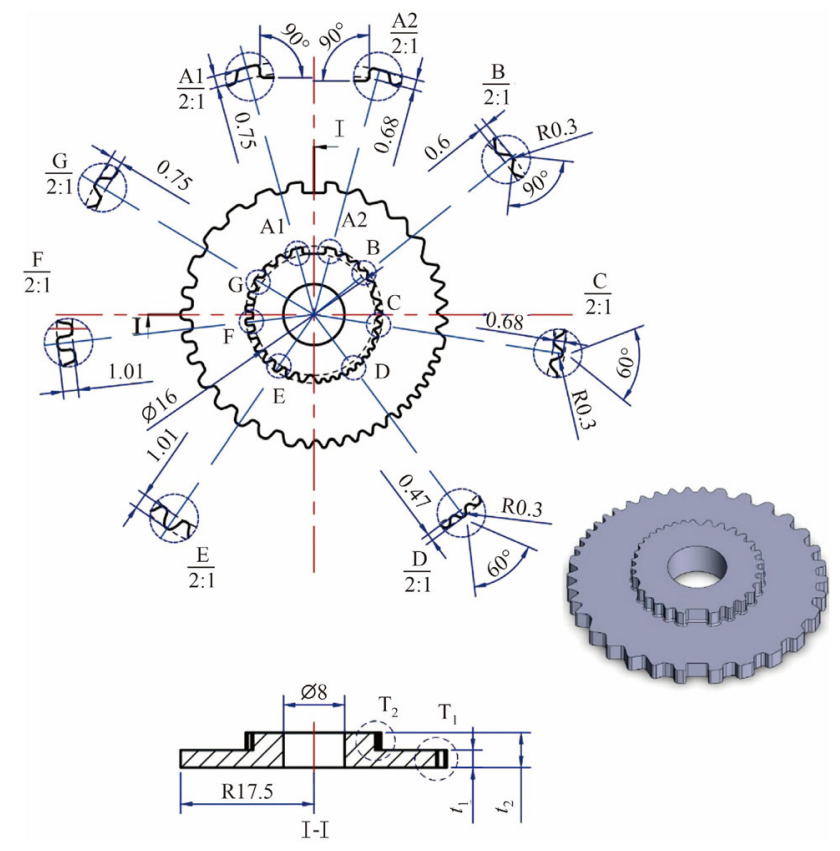

Fig. 2 Details of target duplex gear part (unit: mm)

Table 1 Geometric characteristics related to die roll

\begin{tabular}{lllll}
\hline Tooth & $\begin{array}{l}\text { Corner radius } \\
R / \mathrm{mm}\end{array}$ & $\begin{array}{l}\text { Corner angle } \\
\alpha /\left(^{\circ}\right)\end{array}$ & $\begin{array}{l}\text { Tooth length } \\
/ \mathrm{mm}\end{array}$ & $\begin{array}{l}\text { Gear } \\
\text { modulus } m\end{array}$ \\
\hline $\mathrm{A} 1$ & - & - & 0.75 & 1.42 \\
$\mathrm{~A} 2$ & - & - & 0.68 & 1.09 \\
$\mathrm{~B}$ & 0.3 & 90 & 0.6 & 0.55 \\
$\mathrm{C}$ & 0.3 & 60 & 0.68 & 0.47 \\
$\mathrm{D}$ & 0.3 & 60 & 0.47 & 0.39 \\
$\mathrm{E}$ & - & - & 1.01 & 0.57 \\
$\mathrm{~F}$ & - & - & 1.01 & 0.57 \\
$\mathrm{G}$ & - & - & 0.75 & 0.67 \\
\hline
\end{tabular}

and mandrel. Then, the punch goes down. Once the punch touches the billet, the forming process starts. The teeth of shoulder area are gradually formed by shearing, while the material in the outer area is subject to upsetting, similar to the method proposed by Maeno et al. [14] for fabricating the step stainless steel parts. When the material in the outer area is upset to contact the gear surface of the die, lateral extrusion stage is launched. In this stage, divided flow phenomenon is anticipated. Some material starts to flow back to the shoulder area, contributing to the reduction of die roll. When the outer teeth are completely filled, the local filling stage starts to sharply reduce the die roll.

Experiments were carried out on an H1F200 servo press. Tool setup is shown in Fig. 4. Aluminum 6061 under fully annealed state is selected as the experimental material. 


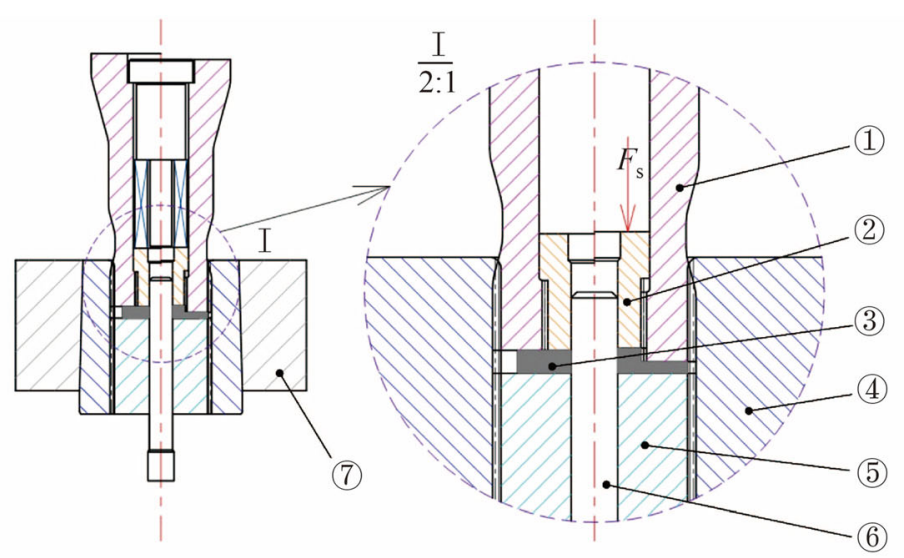

(1) Punch (2) Counter die (3) Billet (4) Die (5) Stationary die (6) Mandrel (7) Die container

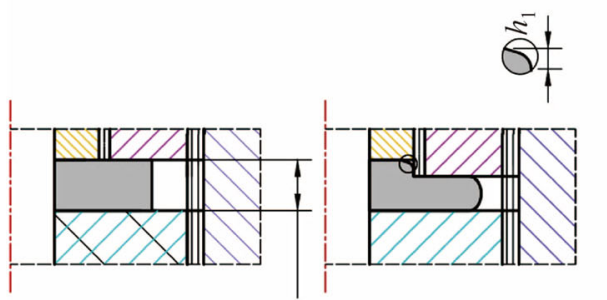

Billet

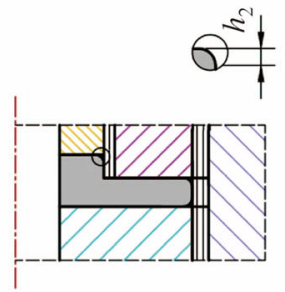

Lateral extrusion

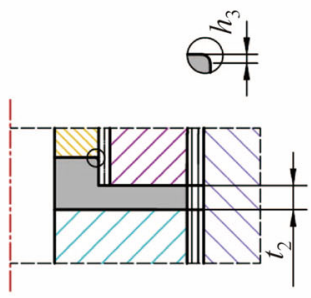

Local filling

Fig. 3 Principle of duplex gear forming method

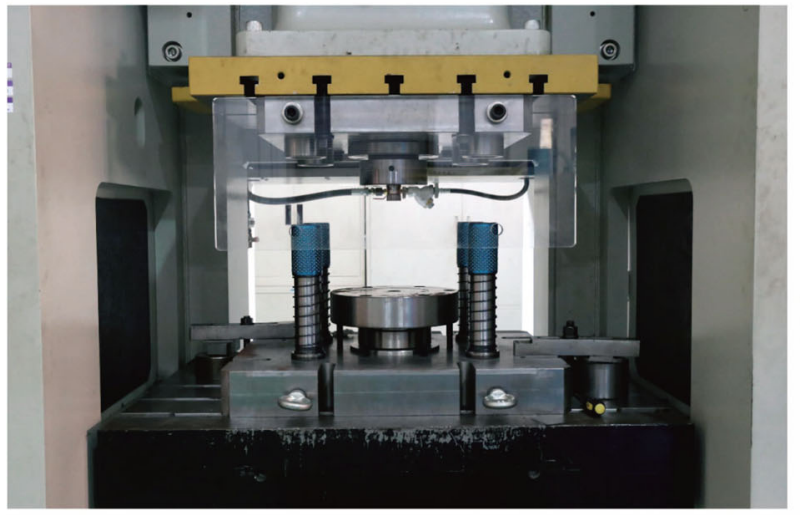

Tool setup

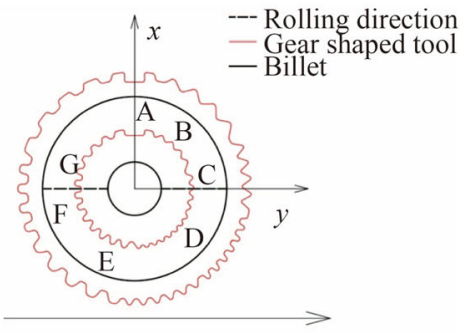

Billet stationary direction

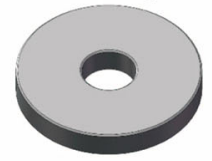

Billet

Fig. 4 Experimental tool setup

Fifty MISUMI SRBN18-B spring discs are installed to provide the counterforce. The stiffness coefficient for each disc spring is $1274 \mathrm{~N} / \mathrm{mm}$. The spring discs could be of various stacking combinations that offer different floating distances and counterforces. In this study, the spring discs are combined with $0.1 \mathrm{~mm}$ shim to create two experimental situations. In one situation, the inner shoulder thickness $\left(t_{2}\right)$ is larger than $t_{0}$; thus, the inner shoulder has been thickened. In another situation, $t_{2}$ is equal to $t_{0}$; thus, the inner shoulder has not been thickened. The thickness of the sheet billet $\left(t_{0}\right)$ is $4.1 \mathrm{~mm}$. Table 2 lists the thicknesses
Table 2 Thicknesses of different areas in two situations

\begin{tabular}{llllll}
\hline Situation & $\begin{array}{l}\text { Sheet } \\
t_{0} / \mathrm{mm}\end{array}$ & $\begin{array}{l}\text { Area } \mathrm{T}_{1} \\
t_{1} / \mathrm{mm}\end{array}$ & $\begin{array}{l}\text { Area } \mathrm{T}_{2} \\
t_{2} / \mathrm{mm}\end{array}$ & $\begin{array}{l}\text { Thicken } \\
\Delta t / \mathrm{mm}\end{array}$ & $\begin{array}{l}\text { Stroke/ } \\
\mathrm{mm}\end{array}$ \\
\hline (a) & 4.1 & 1.90 & 4.7 & 0.6 & 2.20 \\
(b) & 4.1 & 2.05 & 4.1 & 0 & 2.05 \\
\hline
\end{tabular}

of different gear areas in these two situations. For the situation in which the shoulder was thickened $\left(t_{2}>t_{0}\right)$, the thickened value $(\Delta t)$ of the shoulder could be set not only to $0.6 \mathrm{~mm}$, but also other sizes like $0.2 \mathrm{~mm}$ and $0.4 \mathrm{~mm}$, 
while the experiment results showed the same regulations; and in order to make the material flow control influences more clearly, the thickened value $(\Delta t)$ was set as $0.6 \mathrm{~mm}$.

The inner and outer diameters of the ring-shaped billets are $8.0 \mathrm{~mm}$ and $27.3 \mathrm{~mm}$, respectively. The billets were lubricated with RENOFORM MZAN $51 \mathrm{H}$ provided by FUCHS.

The direction of the billets is constant as illustrated in Fig. 4, where the black dash line represents the rolling direction of the sheet. Samples prepared in different stages are scanned using ATOS core scanning equipment to measure the die roll. Three samples were tested to demonstrate the repeatability of the proposed method.

\subsection{Numerical model}

The numerical simulation was conducted using the commercial software Forge NxT1.1. Flow curves were obtained from a cylinder compression test performed at room temperature. Hill's 48 anisotropic model [15] was used as the material model, as expressed

$$
\begin{aligned}
& F\left(\sigma_{22}-\sigma_{33}\right)^{2}+G\left(\sigma_{33}-\sigma_{11}\right)^{2}+H\left(\sigma_{11}-\sigma_{22}\right)^{2}+2 L \sigma_{23}^{2} \\
& \quad+2 M \sigma_{13}^{2}+2 N \sigma_{12}^{2}=\sigma_{0}^{2},
\end{aligned}
$$

where $\sigma_{11}, \sigma_{22}$ and $\sigma_{33}$ are normal stresses, $\sigma_{12}, \sigma_{13}$ and $\sigma_{23}$ shear stresses, $\sigma_{0}$ the yield stress in the rolling direction of the sheet metal. F, $G, H, L, M$, and $N$ are Hill's anisotropic parameters, which can be expressed by Lankford coefficients ( $r$ values). The values of $L$ and $M$ are considered to be equal to $N$ in this study.

$$
\left\{\begin{array}{l}
F=\frac{r_{0}}{r_{90}\left(r_{0}+1\right)}, \\
G=\frac{1}{r_{0}+1}, \\
H=\frac{r_{0}}{r_{0}+1}, \\
N=\frac{\left(r_{0}+r_{90}\right)\left(1+2 r_{45}\right)}{2 r_{90}\left(r_{0}+1\right)} .
\end{array}\right.
$$

Lankford coefficients ( $r$ values) were derived using Eq. (3) through a cube compression test [16], where $\varepsilon_{\mathrm{w}}$ and $\varepsilon_{\mathrm{t}}$ denote the true strains in the width and thickness directions, respectively.

$r=\frac{\varepsilon_{\mathrm{w}}}{\varepsilon_{\mathrm{t}}}$

Table 3 presents the parameters of the Holloman's model and Lankford coefficients.

The forming speed is set to $1 \mathrm{~mm} / \mathrm{s}$. Moreover, shear friction model was used in the simulation [17]. Ring compression test (RCT) [18] was applied to calibrate the shear factor. Figure 5 shows the specimens before and after ring compression test. For initial specimen, the inner
Table 3 Flow curve model and Lankford coefficients (6061-O)

\begin{tabular}{llll}
\hline Holloman's model $\sigma_{\mathrm{f}}$ & \multicolumn{4}{l}{ Lankford coefficient } \\
\cline { 2 - 4 } & $r_{0}$ & $r_{45}$ & $r_{90}$ \\
\hline $218.05 \varepsilon^{0.24}$ & 0.84 & 0.54 & 1.17 \\
\hline
\end{tabular}

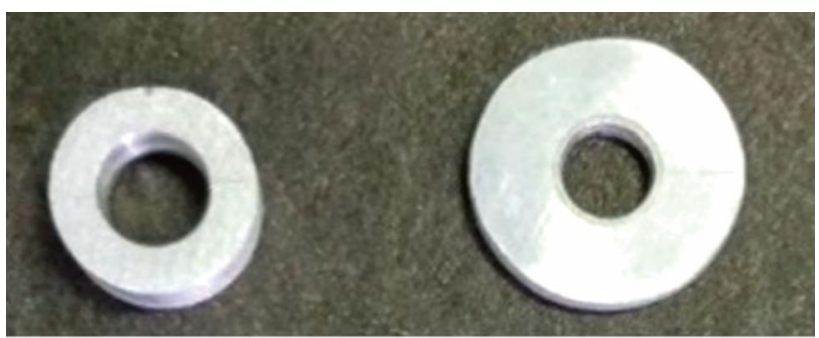

(a)

(b)

Fig. 5 Specimens before and after ring compression test a initial specimen, $\mathbf{b}$ specimen after compression

diameter is $6 \mathrm{~mm}$; the outer diameter is $12 \mathrm{~mm}$; and the thickness is $4.1 \mathrm{~mm}$. The billet was treated with the same oil provided by FUCHS. Three repeat specimens were tested and the inner diameters were changed from $6 \mathrm{~mm}$ to $4.76 \mathrm{~mm}, 4.78 \mathrm{~mm}$ and $4.82 \mathrm{~mm}$, respectively when the reduction in height was $50 \%(2.05 \mathrm{~mm})$. Referring to the curves in Ref. [19], the shear factor is derived as 0.12 .

The stiffness of the counter die is set to $1600 \mathrm{kN} / \mathrm{mm}$. Figure 6 illustrates the schematic of the spring load on the counter die, where $d_{\mathrm{z}}$ represents the floating distance of the counter die, and $g_{\mathrm{z}}$ represents the gap between the counter die and the billet. Therefore, the sum of $d_{\mathrm{z}}$ and $g_{\mathrm{z}}$ yields the difference in thickness $\left(\Delta t=t_{2}-t_{0}\right)$. Three virtual situations were designed to compare the effects of material flow on forming quality. No counter die or counterforce is used in the first situation. In the second situation, the gap size $\left(g_{\mathrm{z}}\right)$ is set to $0.2 \mathrm{~mm}$, and the floating distance of the counter die $\left(d_{\mathrm{z}}\right)$ is set to $0.4 \mathrm{~mm}$. Thus, the change in thickness $\Delta t$ is $0.6 \mathrm{~mm}$. In the third situation, the gap size $\left(g_{\mathrm{z}}\right)$ is set to 0 . Since zero floating distance of the counter die $\left(d_{z}\right)$ represents a constraint of no movement, it is set to a very small value in the simulation, signifying no thickening in this situation. The last two situations could be viewed as the corresponding virtual tests to the experiments.

\section{Results and discussion}

\subsection{Effects of material flow on forming quality}

Forming results obtained from experimental situations (a) and (b) are presented in Fig. 7. In situation (a), defects 


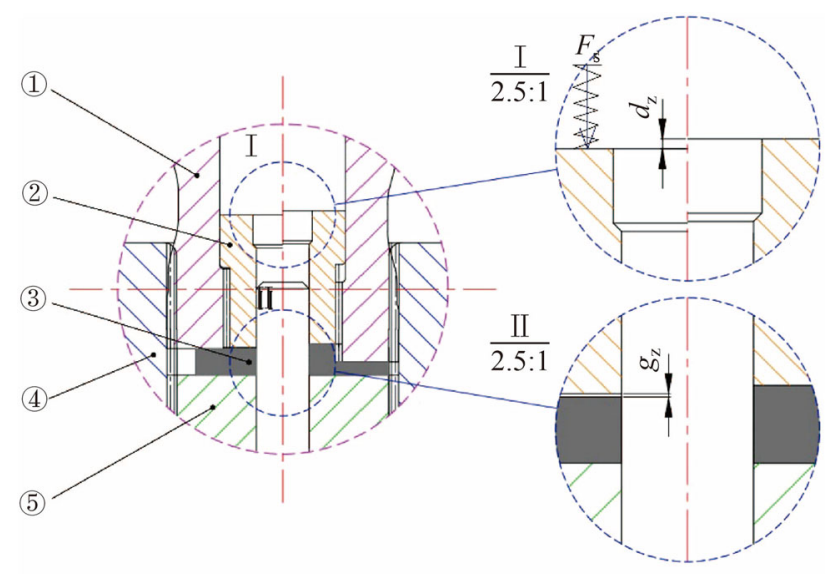

(1) Punch (2) Counter die (3) Billet (4) Die (5) Stationary die

Fig. 6 Schematic of spring load on counter die

appeared in the shearing zone $\left(\mathrm{T}_{2}\right)$. The section a1 in tooth A1 was selected to examine the evolution of defects during the forming process. As shown in Fig. 7c, no defects appeared before the stroke reached $73.2 \%$. When the stroke reached $87.0 \%$, a crack started to emerge in the shearing zone and a sink was observed at the center position. In the subsequent forming stages, when the stroke reached $96.1 \%$, the observed sink was reduced, whereas the crack became increasingly severe. In situation (b), no defects such as cracks or material sinks appeared.

Material flow is generally regarded as a major factor influencing the forming quality of the part [19]. To determine the difference of material flow clearly, the grain flow lines in section a1 was analyzed on a microscopic scale. As shown in Fig. 8a, when the stroke is $73.2 \%$, the shearing

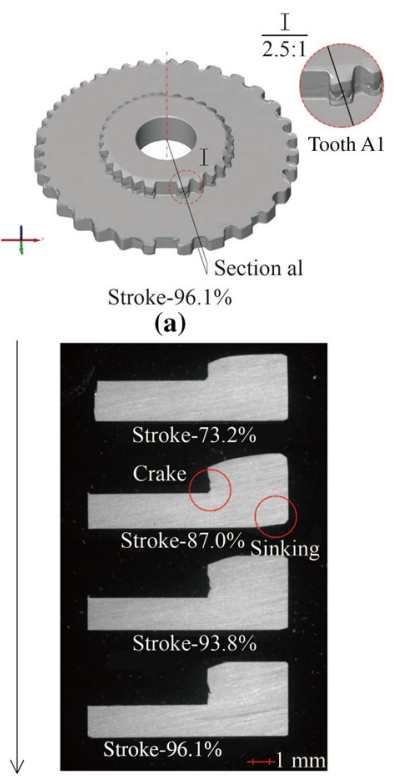

(c)

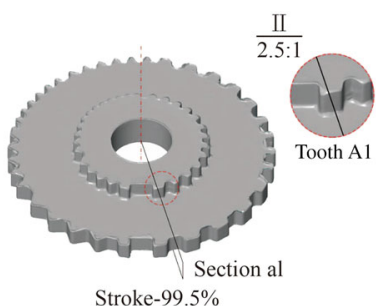

(b)

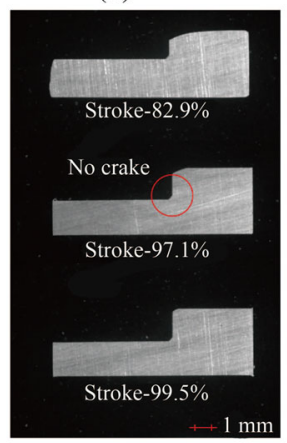

(d)
Fig. 7 Macroscopic view of experimental results zone is straight and no defects appeared. When the stroke is $87.0 \%$, the shearing zone is distorted, and the grain flow lines in $\mathrm{A} 2$ and $\mathrm{B} 2$ are cracked. When the stroke is $93.8 \%$, the crack became more severe. As shown in Fig. 8b, the shearing zone is very straight, and the grain flow lines are continuous. Specifically, no crack was observed in this situation.

To clearly understand the characteristics of material flow and defects, velocity distribution of the material flow was plotted in Fig. 9 in terms of three virtual situations mentioned before, namely no counter die, $\Delta t=0.6 \mathrm{~mm}$, and $\Delta t=0$. During the shearing stage, the material was in contact with the punch and flowed outward; the material velocity in the shoulder area $T_{2}$ was zero in all three situations. The shearing zone was straight in this stage. In the lateral extrusion stage, the material started to exhibit divided flow. For the situation without the counter die, the velocity in $\mathrm{T}_{2}$ was between 0 and $3.6 \mathrm{~mm} / \mathrm{s}$ when the stroke was $87.0 \%$. A gap appeared in the shearing zone, and the material flow direction was distorted. For the situation of $\Delta t=0.6 \mathrm{~mm}$, when the stroke was $87.0 \%$, the velocity in $\mathrm{T}_{2}$ was between 0 and $1.2 \mathrm{~mm} / \mathrm{s}$. A gap also emerged in the shearing zone, and the material flow direction was distorted as well. Regarding the last situation, when the stroke was $92.7 \%$, the velocity in $\mathrm{T}_{2}$ was between 0 and $1.2 \mathrm{~mm} / \mathrm{s}$, and the material mainly flowed into the die roll area of $\mathrm{T}_{2}$. When the stroke was $96.1 \%$, for the situation without counter die, the velocity in $\mathrm{H} 1$ area was approximately $6 \mathrm{~mm} / \mathrm{s}$; gaps were observed in $\mathrm{G} 1$ and $\mathrm{H} 1$, and sinking was observed in $\mathrm{J} 1$. While for the situation of $\Delta t=0.6$ $\mathrm{mm}$, the inward flow of the material was limited; no gap or sinking appeared in H1, but the gap in G2 was not ameliorated. For the last situation, inward flow of the material was controlled, with the material flowing only to the die roll area in $\mathrm{T}_{2}$; the direction of material flow in E3 and F3 was not distorted, and no gap or sinking emerged in this situation.

Figure 10 shows the effective strain distributions in section a1 for the virtual situations of $\Delta t=0.6 \mathrm{~mm}$ and 0 . It could be seen that the strain in the shearing zone is much larger than the other areas, which indicated severe material deformation of inner teeth area. To determine the stress state in the shearing zone, first principle stress $\left(\sigma_{1}\right)$ is investigated as shown in Fig. 11. The areas having positive $\sigma_{1}$ are subject to tension stress state, which can easily cause crack defects.

According to Fig. 11, for virtual situation (a), $\sigma_{1}$ in area M1 (87\% stroke) is positive, and larger than the other areas. Once the stroke is up to $96.1 \%, \sigma_{1}$ in area N1 is much larger than the one in M1. For virtual situation (b), $\sigma_{1}$ in area M2 (97.1\% stroke) is negative, and continues to be a negative value in area $\mathrm{N} 2$ (99.5\% stroke). It could be concluded that in situation (a), the local area of the inner 


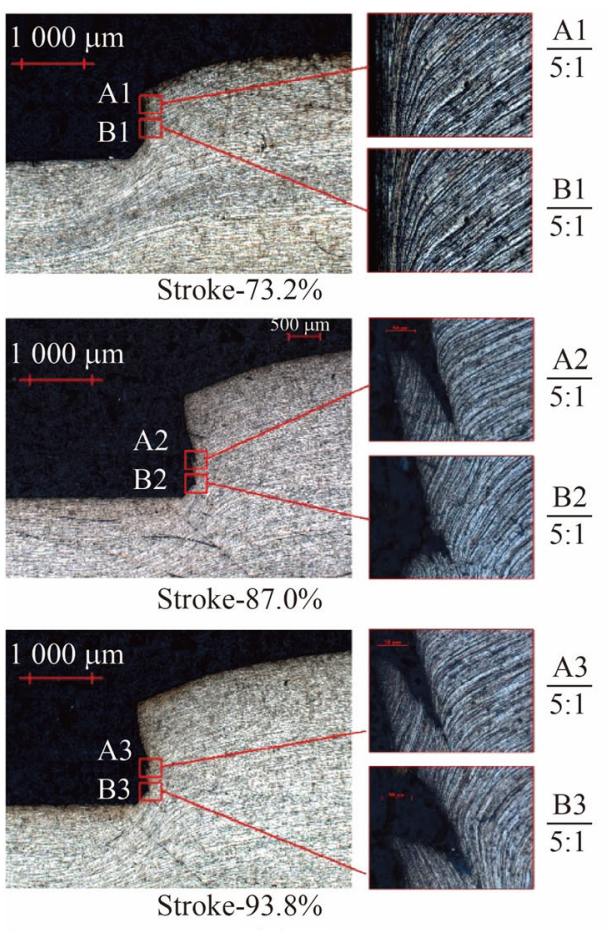

(a)
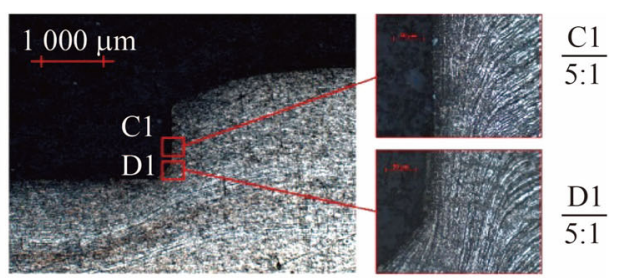

Stroke- $82.9 \%$
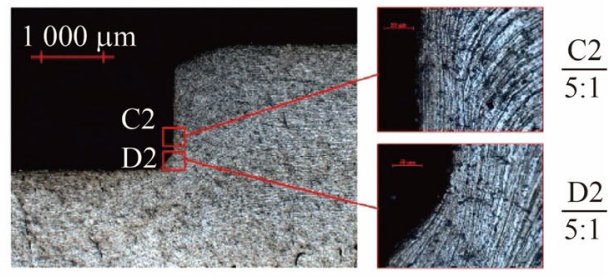

Stroke- $97.1 \%$
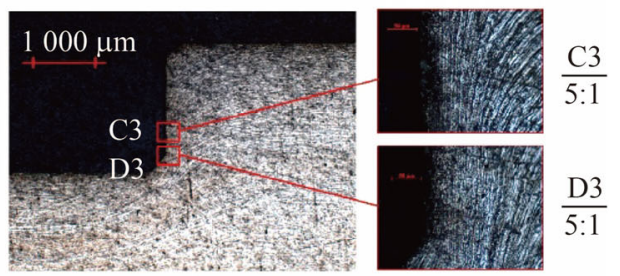

Stroke-99.5\%

(b)

Fig. 8 Grain flow lines in section a1 a $\Delta t=0.6 \mathrm{~mm}, \mathbf{b} \Delta t=0$
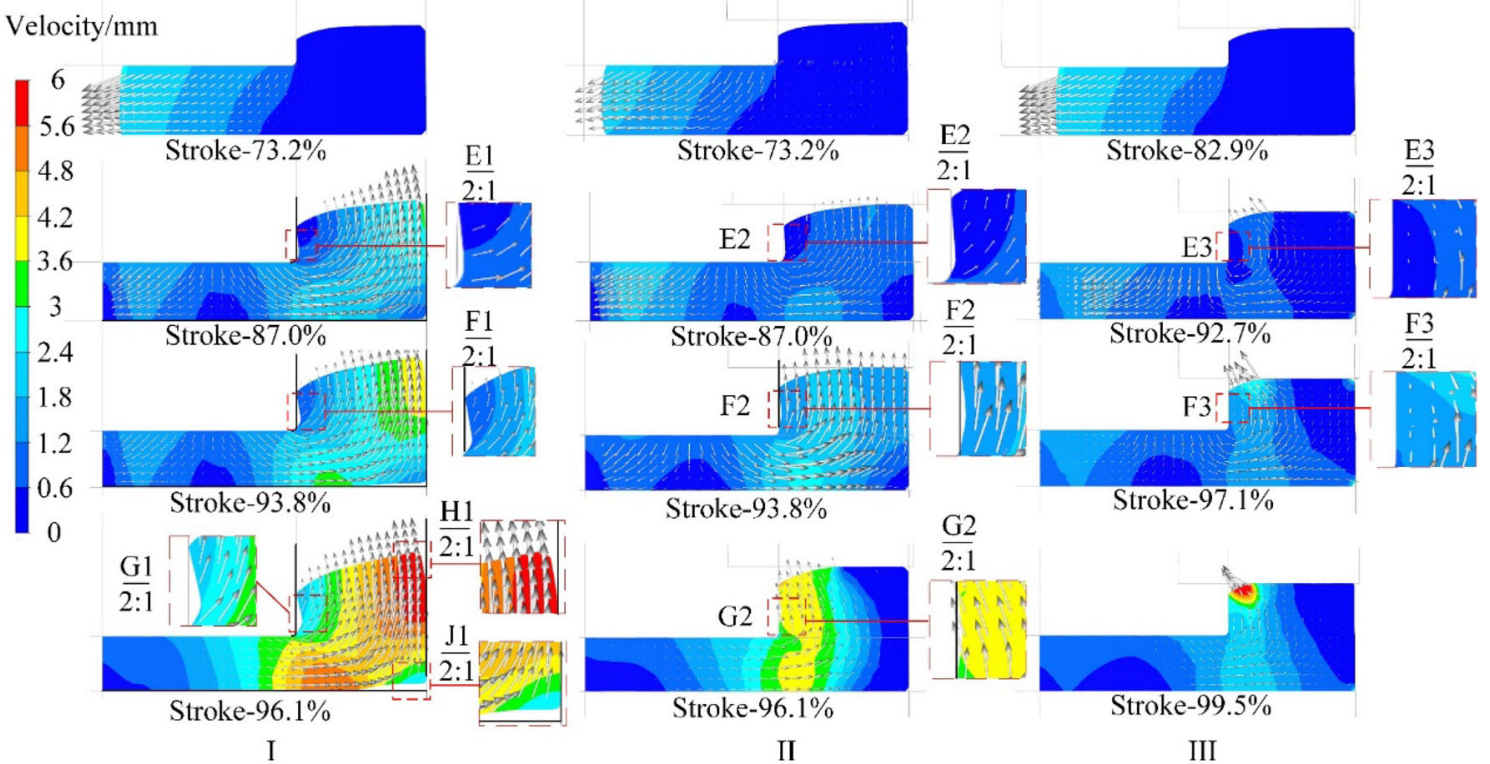

Fig. 9 Velocity distribution of material flow in three virtual situations I no counter die, II $\Delta t=0.6 \mathrm{~mm}$, III $\Delta t=0$

teeth is subjected to tension stress state, while in situation (b), the same is subjected to compression stress state. The differences of stress stated could explain why the crack occurs in situation (a), while no crack defect is observed in situation (b).

\subsection{Die roll evolution}

To determine the evolution of the die roll height in the shoulder area $\left(\mathrm{T}_{2}\right)$, the samples obtained from various stages of the experiment were compared with the target part. For the teeth in section a1, the evolution of the die roll in different stages could be clearly observed in Fig. 12. The 
Effective strain

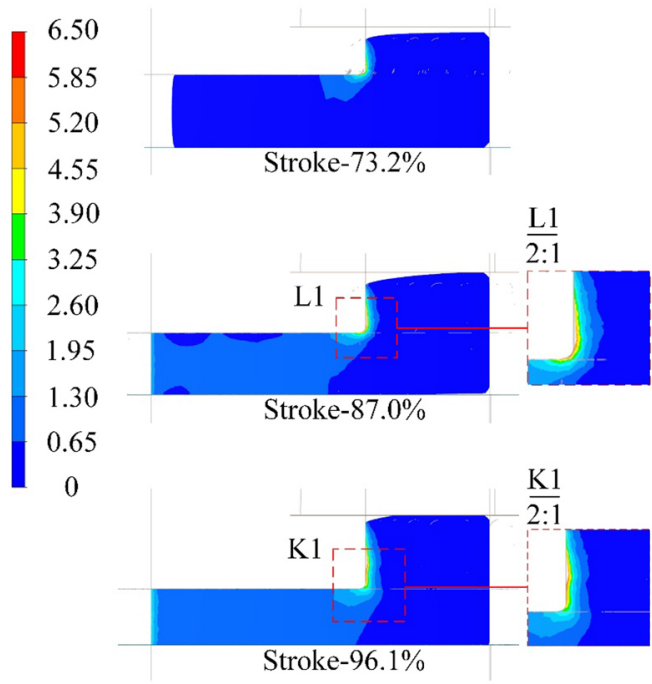

(a)
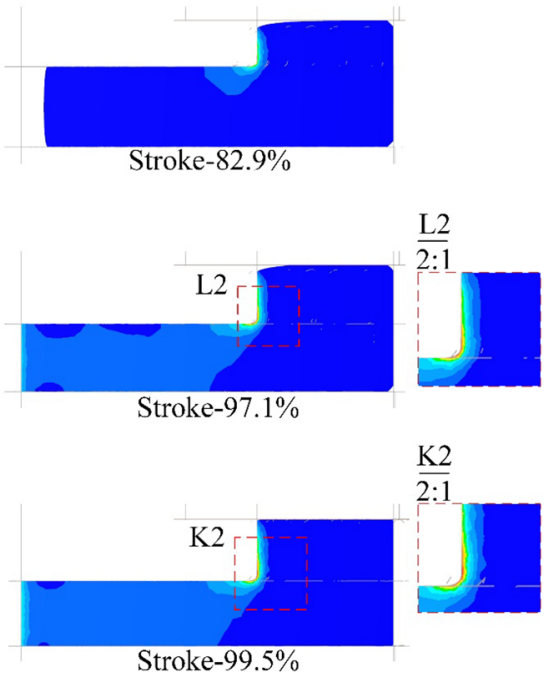

(b)

Fig. 10 Strain distribution of section a1 in simulation a $\Delta t=0.6 \mathrm{~mm}, \mathbf{b} \Delta t=0$

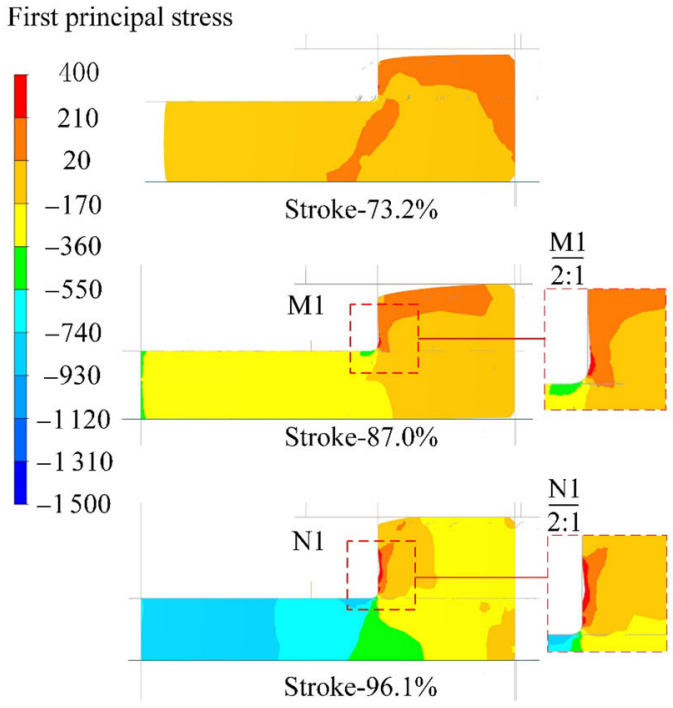

(a)

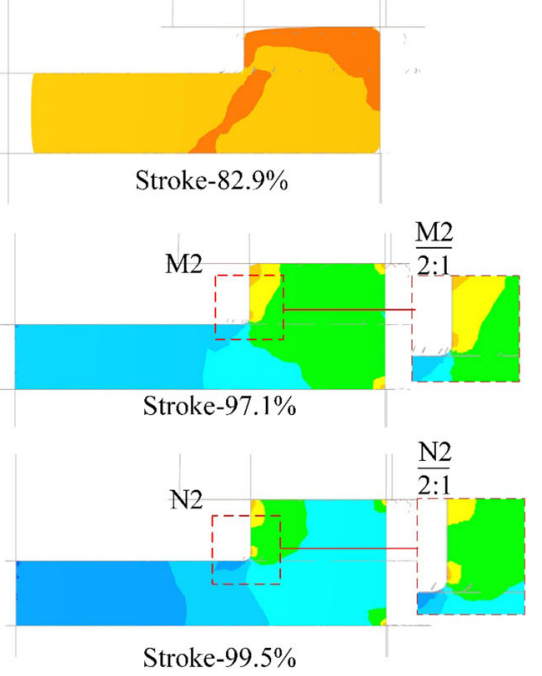

(b)

Fig. 11 First principal stress distribution of section a1 a $\Delta t=0.6 \mathrm{~mm}, \mathbf{b} \Delta t=0$

die roll in the first stage of shearing and upsetting was obvious. The die roll height was $0.4 \mathrm{~mm}$. In the lateral extrusion stage, the die roll height was changed to $0.32 \mathrm{~mm}$. In the local filling stage, the die roll decreased continually, with the height $0.05 \mathrm{~mm}$. As revealed by the results presented in the right panel of Fig. 12, the die rolls of various teeth decreased.

The material flow during the forming of teeth A1 and A2 is shown in Fig. 13. In the shearing and upsetting stage, the material flowed towards the outer area, meanwhile the shoulder area was a dead zone. Once the stroke reached $92.7 \%$, the divided material flow occurred, and the material started flowing to the shoulder area. When the stroke changed from $96.6 \%$ to $97.6 \%$, the divided material flowed into the outer area $\left(\mathrm{T}_{1}\right)$ and the shoulder area could be seen clearly. Thus, the teeth in the outer area were better filled, and the die roll in the shoulder area was reduced as well. When the stroke changed from $98.3 \%$ to $99.5 \%$, the teeth in the outer area were nearly filled, and the material was limited to the shoulder area.

Figure 14 presents the die roll heights observed for various types of teeth in different stages of the forming process. The tooth length considerably affected the die roll size in the shearing and upsetting stage. The tooth that had 

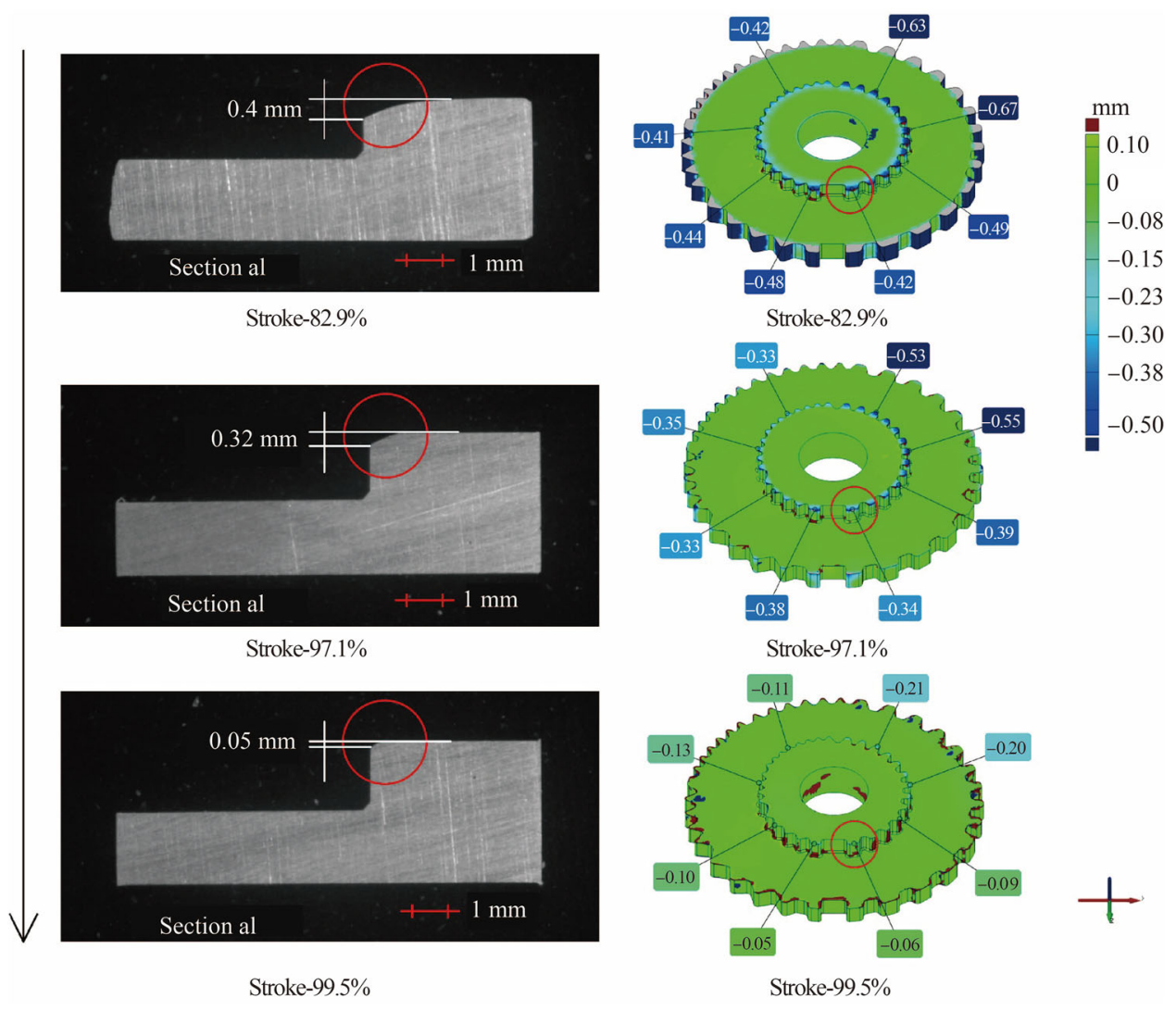

Fig. 12 Die roll evolution $(\Delta t=0)$

the longest length, namely tooth $\mathrm{F}$, had the largest die roll height. By contrast, the shortest tooth, namely tooth $\mathrm{D}$, exhibited the smallest die roll height. In the shearing stage, tooth $\mathrm{D}$ had the smallest die roll among all teeth, with the die roll height being approximately $0.33 \mathrm{~mm}$, which was nearly $19.4 \%(0.33 \mathrm{~mm} / 1.7 \mathrm{~mm})$ of the working length. Tooth $\mathrm{F}$ had the largest die roll, with the die roll height being approximately $0.62 \mathrm{~mm}$, which was nearly $36.5 \%$ $(0.62 \mathrm{~mm} / 1.7 \mathrm{~mm})$ of the working length. In the lateral extrusion stage, when the stroke was $97.1 \%$, the die roll decreased. When the stroke was $99.5 \%$, the height of tooth D was changed to $0.077 \mathrm{~mm}$, which was nearly $23.3 \%$ $(0.077 \mathrm{~mm} / 0.33 \mathrm{~mm})$ of the height observed when the stroke was $82.9 \%$. For tooth $\mathrm{F}$, the die roll height was approximately $0.143 \mathrm{~mm}$, which was nearly $23.1 \%$ $(0.143 \mathrm{~mm} / 0.62 \mathrm{~mm})$ of the height observed when the stroke was $82.9 \%$.

Figure 15 illustrates load-stroke curves of the forming process. In the shearing and upsetting stage (stroke range: $0-82.9 \%$ ), the load was lower than $200 \mathrm{kN}$. When the outer teeth started to form through lateral extrusion (stroke range: $82.9 \%-97.6 \%$ ), the load increased rapidly. In the lateral extrusion stage, divided material flow occurred when the stroke was $92.7 \%$. When the stroke was $97.6 \%$, the teeth in the outer area were nearly filled. When the stroke was from $97.6 \%$ to $100 \%$, the material flow was limited to the die roll area, indicating a local filling stage. When the stroke was $99.5 \%$, the die roll height was relatively small (see Fig. 14). Accordingly, to protect the die set, the stroke of $99.5 \%$ was considered the optimal level.

\section{Conclusions}

The present work put forward a new SBMF method including three stages for fabricating a duplex gear in one stroke. A duplex gear part with extremely small die roll could be obtained through utilizing material flow control during forming. The experiment and simulation draw out the following conclusions:

(i) By analyzing the velocity in simulation, the critical stroke when the material started divided flow and local filling could be determined. In the situation of unthickened shoulder area, since the stroke reached $92.7 \%$, the material started the divided flow, and when the stroke became $97.6 \%$, the outer area was filled and material was limit to flow into the local area. 


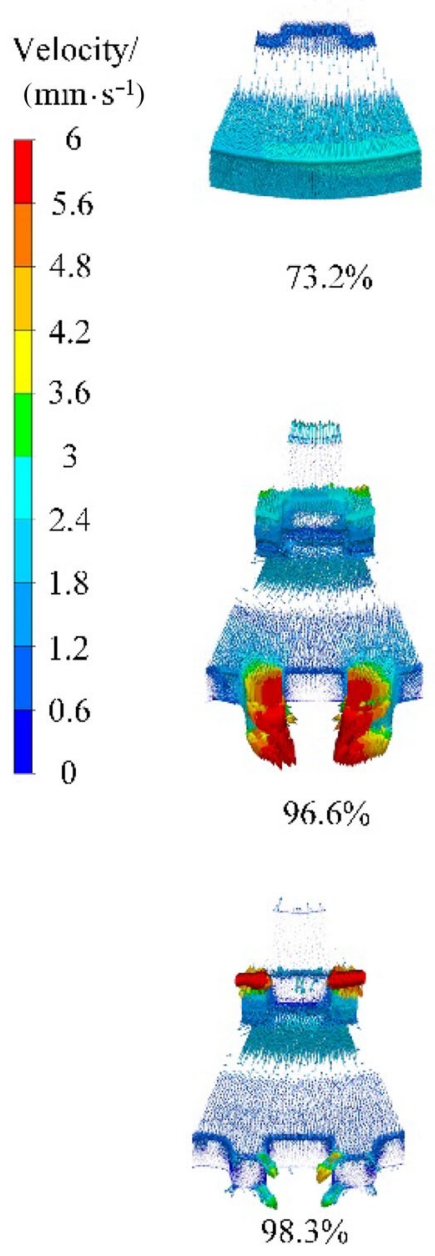

Fig. 13 Material flow of teeth A1 and A2 $(\Delta t=0)$

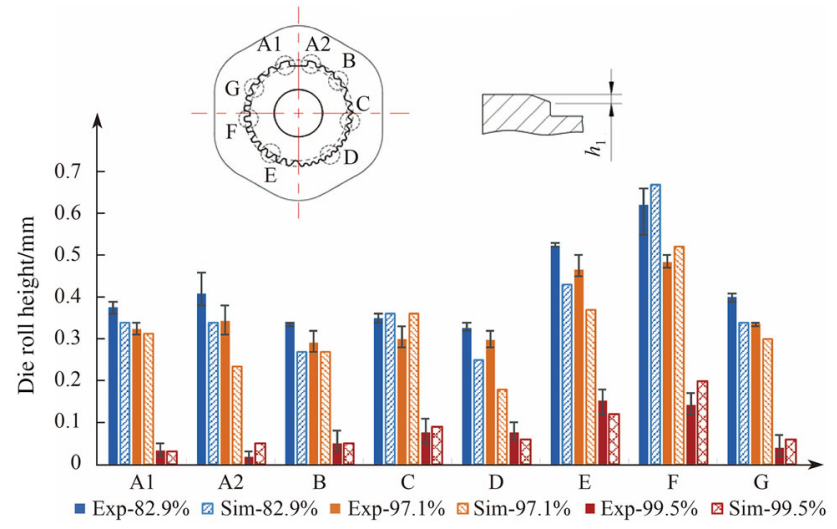

Fig. 14 Die roll height observed for different strokes $(\Delta t=0)$

(ii) Die roll in the shoulder area, which appeared in the shearing stage, would be decreased because of the material flow inside the should area. Both

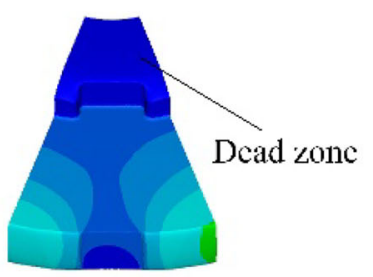

$82.9 \%$

Material flow outside

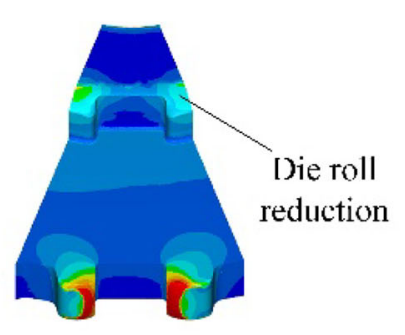

$97.1 \%$

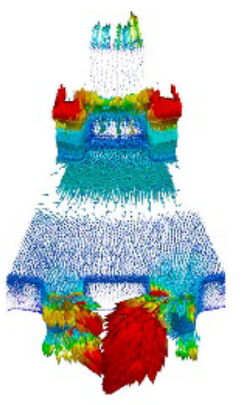

$97.6 \%$

Material divided flow

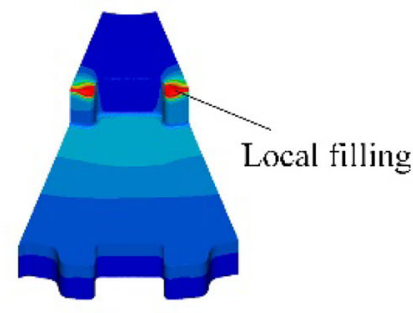

$99.5 \%$

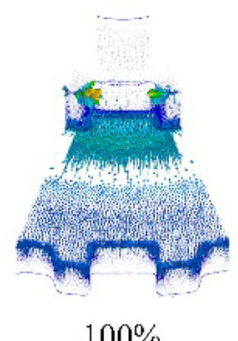

Local filling

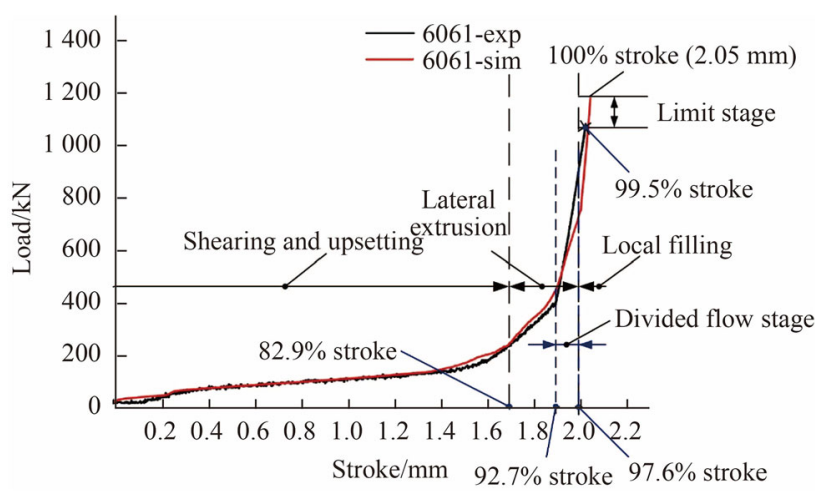

Fig. 15 Load-stroke curves $(\Delta t=0)$

lateral extrusion and local filling contribute to the flowing inside of the material.

(iii) The forming quality is strong related to the material flow. If the material in the shoulder area 
is too fast or distorted, defects like cracks caused by tension stress would appear in the shearing zone of the duplex gear. It is found that when the shoulder thickness is controlled not to be thickened, the crack in the shearing zone could be avoided.

Acknowledgements This work was supported by the National Natural Science Foundation of China (Grant No. 51475296).

Open Access This article is distributed under the terms of the Creative Commons Attribution 4.0 International License (http://crea tivecommons.org/licenses/by/4.0/), which permits unrestricted use, distribution, and reproduction in any medium, provided you give appropriate credit to the original author(s) and the source, provide a link to the Creative Commons license, and indicate if changes were made.

\section{References}

1. Sonsino CM, Ratzi R (2004) Warm powder compaction substitutes conventionally double pressed and double sintered synchroniser hubs. Powder Metall 47(4):352-357

2. Hayashi K (2006) Tool engineering for fineblanking and sheet metal forging complex work. J Jpn Soc Technol Plast 47(546):554

3. Kondo K, Maeda K (1972) Development of a new precision shearing process: opposed dies shearing process. In: Proceedings of the twelfth international machine tool design and research conference. Macmillan Education UK, pp 61-68

4. Kwak TS, Kim YJ, Bae WB (2002) Finite element analysis on the effect of die clearance on shear planes in fine blanking. J Mater Process Technol 130(11):462-468

5. Liu Y, Cheng T, Hua L et al (2017) Research on the effect of ultrasonic vibration on the roll-over during the fine blanking process. J Mech Sci Technol 31(2):835-843
6. Liu Y, Tang B, Hua L et al (2018) Investigation of a novel modified die design for fine-blanking process to reduce the dieroll size. J Mater Process Technol 260:30-37

7. Fan WF, Li JH (2009) An investigation on the damage of AISI1045 and AISI-1025 steels in fine-blanking with negative clearance. Mater Sci Eng, A 499(1-2):248-251

8. Tanaka T, Hagihara S, Tadano Y et al (2011) Analysis of shear droop on cut surface of high-tensile-strength steel in fine-blanking process. Mater Trans 52(3):447-451

9. Huang X, Xiang H, Zhuang XC et al (2011) Improvement of dieroll quality in compound fine-blanking forming process. Adv Mater Res 337:236-241

10. Luo C, Chen Z, Zhou K et al (2017) A novel method to significantly decrease the die roll during fine-blanking process with verification by simulation and experiments. $\mathrm{J}$ Mater Process Technol 250:254-260

11. Gröbel D, Schulte R, Hildenbrand P et al (2016) Manufacturing of functional elements by sheet-bulk metal forming processes. Prod Eng 10(1):63-80

12. Merklein M, Allwood JM, Behrens BA et al (2012) Bulk forming of sheet metal. CIRP Ann Manuf Technol 61(2):725-745

13. Mori K, Nakano T (2016) State-of-the-art of plate forging in Japan. Prod Eng 10(1):81-91

14. Maeno T, Mori K, Hori A (2014) Application of load pulsation using servo press to plate forging of stainless steel parts. J Mater Process Technol 214(7):1379-1387

15. Hill R (1948) A theory of the yielding and plastic flow of anisotropic metals. Proceed R Soc Lond 193(1033):281-297

16. Sun X, Zhuang X, Zhao Z (2018) Investigation of anisotropy effects on sheet-bulk forming of duplex gear parts. Int J Mech Sci 140:51-59

17. Zhang DW, Ou H (2016) Relationship between friction parameters in a Coulomb-Tresca friction model for bulk metal forming. Tribol Int 95:13-18

18. Sofuoglu H, Rasty J (1999) On the measurement of friction coefficient utilizing the ring compression test. Tribol Int 32(6):327-335

19. Vierzigmann U, Koch J, Merklein M et al (2012) Material flow in sheet-bulk metal forming. Key Eng Mater 504-506:1035-1040 